\title{
Test method to assess interface adhesion in composite bonding
}

\author{
Sofia Teixeira de Freitas ${ }^{*}$ and Jos Sinke
}

\author{
*Correspondence: \\ s.teixeiradefreitas@tudelft.nl \\ Faculty of Aerospace Engineering, \\ Delft University of Technology, \\ Kluyverweg 1, 2629HS Delft, \\ Netherlands
}

\begin{abstract}
This paper introduces a new type of peel tests dedicated to composite bonding: Composite Peel Tests. This test is inspired on the standard floating roller peel test widely used for metal bonding.

The aim of this study is to investigate the potential of the Composite Peel Test to assess interface adhesion in composite bonded structures. To this end, peel tests were performed with nine different types of adhesives and at two environmental temperatures, room temperature and $+80^{\circ} \mathrm{C}$. The results were compared with the standard floating roller peel tests with Aluminium adherends.

The results show that when using the Composite Peel Test good interface adhesion results either in cohesive failure of the adhesive or intra-laminar failure of the composite, while bad adhesion results in adhesive failure. In most cases of good interface adhesion, increasing the temperature favors cohesive failure of the adhesive in detriment of intra-laminar failure of the composite.

Peel strengths can be used as a quality indicator of interface adhesion only if using exactly the same type of flexible adherend (peeling-off member). Nevertheless, if cohesive failure is the dominant failure mode, the comparison between adhesives' peel strength is consistent disregarding of the type of peel-off adherend. Composite Peel Tests are suitable to assess interface adhesion of composite bonded structures.
\end{abstract}

Keywords: Peel tests; Composites; Adhesion; Interface; Composite bonding

\section{Background}

The use of composite materials in aerospace industry has significantly increased in the last few years. Operating since 2011, with more than $50 \%$ of its structural weight made of composites, the Boeing 787 Dreamliner is an unquestionable testimony to this fact. Adhesive bonding offers major advantages for joining composites, since it avoids the hazards of drilling holes in these materials (fibre breaking, stress concentrations, black dust, etc.).

In order to avoid interfacial failure in service of bonded composite parts, it is essential to guarantee good adhesion properties at the interfaces. Industry practices should ensure that the composite parts are properly bonded together, and that this bond will endure.

Currently, interface adhesion is assessed by destructive testing. For metal bonding, a widely accepted industrial test to secure a proper bond is the standard floating roller peel test [1]. A cohesive failure when peeling-off the aluminium part ensures that the adherends are properly bonded and that this bond will endure. This is a fast and reliable

(c) 2015 Teixeira de Freitas and Sinke; licensee Springer. This is an Open Access article distributed under the terms of the Creative Commons Attribution License (http://creativecommons.org/licenses/by/4.0), which permits unrestricted use, distribution, and reproduction in any medium, provided the original work is properly credited. 
test to assess metal bonding adhesion. Significant research has been performed using these type of peel test for metal bonding with diverse objectives, including adhesives screening, effect of surface pre-treatments, bond durability, etc. [2-4]. Diverse studies have also investigated the adherends effects in the floating roller peel test. It has been found that the peel strength measured is a combination of the true interface adhesion strength plus work expended in the plastic deformation of the thin adherend. Therefore the mechanical characteristics of the thin adherend have a significant effect on the measured peel load [5-7].

For composite bonding, such test method is yet to be developed. The existing standard tests methods are optimized for metal bonding. A simple and straight forward test coupon is needed, that reveals the adhesion of composite bonding and evaluates the interface of interest. Few studies have been found on the development of rapid peel tests for composite bonding. Van Voast [8] and Flinn [9] have suggested a Rapid Test method (RAT) for adhesion in order to evaluate surface preparation of composite parts. The RAT is a modification of the floating roller peel tests, in which a rigid aluminium adherend is bonded to a flexible one-ply-thick composite adherend. In a second stage, a thin Aluminium adherend is bonded to the flexible one-ply-thick composite with a backing adhesive. The results are promising however the specimens require two bonding processes, one for the adhesive being tested and one extra for the backing adhesive. In addition to this, the specimen is a hybrid bonded joint, an Aluminium rigid adherend is bonded to a composite thin adherend. The effect of different adherend materials on the interface performance might be an extra limitation to this test and might not be representative of the real composite bonded part.

Another modification to the floating roller peel tests is suggested by Holtmannspotter [10], in which the aluminium rigid adherend is replaced by a composite rigid adherend. The thin adherend remains of Aluminium as in the standard test. However, due to the asymmetry of the floating roller peel test, the interface being tested is the one on the thin adherend. Therefore, if using Aluminium for the thin adherend, the tested interface is the Aluminium/adhesive and not the one of interest, composite/adhesive.

Further use of peel tests is reported in Riul et al. (2012) [11]. In this study peel tests are used to compare the interlaminar strength of composite laminates with different manufacturing process. This shows the wide potential of peel tests, not only limited to secondary bonding applications but also to co-cured composite laminates.

In this research a new Composite Peel Test (CPT) for assessing interface adhesion of composite bonded structures is presented. The test method is fast, robust and has a potential for multi-purpose: static adhesion, bond durability, surface and adhesives screening and, ultimately, it can be used as in-process test coupon for manufacturing control of composite bonded parts. This study is the follow up of a the previous study performed by the authors in which different combination of adherend composite vs. Aluminium was investigated [12].

In this paper, the CPT is applied to nine different adhesives and tested at two environmental temperatures. The aim is to investigate the potential of CPT to assess interface adhesion of composite bonded parts. The effect of environmental temperature and adhesive material on the loads and failure mechanism of the CPT are investigated. Furthermore, the results are compared with the standard floating roller peel tests for metal bonding. 


\section{Methods}

Standard floating roller peel tests (FRPT) and the newly developed Composite Peel Test (CPT) were performed for nine different adhesives, at room temperature (RT) and $+80^{\circ} \mathrm{C}$ (high temperature - HT).

\section{Materials and specimens}

The standard floating roller peel specimens were based on the ASTM standard D3167 [1]. A $1.6 \mathrm{~mm}$ thick aluminium sheet (rigid adherend) was adhesively bonded to a $0.5 \mathrm{~mm}$ thick aluminium sheet (flexible adherend). During testing, the flexible adherend is peeled off from the rigid adherend. Both aluminium adherends were clad Aluminium alloy 2024. Prior to bonding, the aluminium surfaces were pre-treated with chromic acid anodizing and primed with BR 127 (Cytec Engineered Materials, Tempe, Arizona, USA).

The CPT is a modification of the ASTM D3167 floating roller peel tests. The adherends are Carbon Fiber Reinforced Polymer (CFRP) laminates instead of aluminium sheets. The purpose is to apply CPT for composite bonding, as floating roller peel tests is being applied for metal bonding. The CFRP were prepared from unidirectional pre-preg consisting of HexPly 8552 epoxy matrix in combination with AS4 carbon fiber (Hexcel Corporation, Stamford, Connecticut, USA). This prepreg was used for a lay up of ten plies $\left[0^{\circ} / 90^{\circ} / 0^{\circ} / 90^{\circ} / 0^{\circ}\right]_{s}$ to produce the rigid composite adherend with approximately 2.4 $\mathrm{mm}$ thickness. A lay up of two plies $\left[0^{\circ} / 90^{\circ}\right]$ was used to produce the flexible composite adherend with approximately $0.37 \mathrm{~mm}$ thickness. The stacking sequence was optimized in a pre-study and it is further explained in a previous paper of the authors [12]. The plies were autoclave cured at $180^{\circ} \mathrm{C}$ for $120 \mathrm{~min}$, under 6 bars pressure. Prior to bonding, the CFRP panels were abraded with sand paper and then wiped clean with an acetone-soaked cloth.

The tests were performed to nine epoxy adhesives. Table 1 shows a list of the adhesives, their manufacturer and corresponding curing cycles. All adhesives were cured in the autoclave under 3 bars pressure, except Supreme 10HT which was out-of-autoclave cured using a vacuum bag and an oven.

Two types of specimens were produced for each adhesive: FRPT specimens (metal bonding) and CPT specimens (composite bonding) - see Figure 1.

The bonded panels were $100 \mathrm{~mm}$ wide by $300 \mathrm{~mm}$ long. After cured, the panels were water jet cut into $25 \mathrm{~mm}$ wide specimens. Figure 2 shows a drawing of the tests panels. The final adhesive thickness was determined by subtracting from the total thickness, the thicknesses of the adherends. The average \pm standard deviation bondline thickness was $0.26 \pm 0.06 \mathrm{~mm}$.

\section{Experimental procedure}

The experimental procedure was based on the ASTM standard D3167 [1]. Testing was carried out using an electro mechanic Zwick machine with maximum capacity of $20 \mathrm{kN}$, coupled with a load cell of $1 \mathrm{kN}$. The testing speed was $125 \mathrm{~mm} / \mathrm{min}$. Figure 3 shows the tests set up of the peel test. A temperature chamber was coupled to the testing machine to perform tests at $+80^{\circ} \mathrm{C}$. A total of three specimens were tested in each test condition. During tests, the load and the cross head displacement were recorded. 
Table 1 List of adhesives and corresponding type, manufacturer, curing cycle and properties at room temperature ( $T_{g}$ : glass transition temperature, d: dry, w: wet)

\begin{tabular}{|c|c|c|c|c|c|c|}
\hline Adhesive & Type & Manufacturer & Cure cycle (temperature, time) & Lap shear strength [MPa] & Peel strength $[\mathrm{N} / 25 \mathrm{~mm}]$ & $T_{g}{ }^{\circ} \mathrm{C}$ \\
\hline FM73 & Epoxy film & Cytec $^{1}$ & $120^{\circ} \mathrm{C}, 60 \mathrm{~min}$ & 45 & 285 & $\overline{101 d / 75 w}$ \\
\hline EA9695 & Epoxy film & Henkel $^{2}$ & $120^{\circ} \mathrm{C}, 60 \mathrm{~min}$ & 35 & 90 & $122 d$ \\
\hline EA9696 & Epoxy film & Henkel $^{2}$ & $120^{\circ} \mathrm{C}, 90 \mathrm{~min}$ & 43 & 356 & $122 d / 106 w$ \\
\hline EA9686 & Epoxy film & Henkel $^{2}$ & $120^{\circ} \mathrm{C}, 90 \mathrm{~min}$ & 36 & 245 & $133 d$ \\
\hline AF163-2 & Epoxy film & $3 \mathrm{M}^{3}$ & $120^{\circ} \mathrm{C}, 60 \mathrm{~min}$ & 41 & 340 & $108 d / 82 w$ \\
\hline AF191 & Epoxy film & $3 \mathrm{M}^{3}$ & $150^{\circ} \mathrm{C}, 60 \mathrm{~min}$ & 39 & 219 & - \\
\hline AF3109-2 & Epoxy film & $3 \mathrm{M}^{3}$ & $120^{\circ} \mathrm{C}, 60 \mathrm{~min}$ & 40 & 218 & - \\
\hline L-8100 NE & Epoxy film & $\mathrm{LL}^{4}$ & $150^{\circ} \mathrm{C}, 60 \mathrm{~min}$ & 22 & 128 & $121 d$ \\
\hline Supreme10HT & Epoxy paste & Master bond ${ }^{5}$ & $120^{\circ} \mathrm{C}, 60 \mathrm{~min}$ & 25 & 200 & - \\
\hline
\end{tabular}

${ }_{1}^{1}$ Cytec Engineered Materials, Tempe, Arizona, USA.

${ }^{2}$ Henkel, Düsseldorf, Germany.

3M, Maplewood, Minnesota, USA.
${ }^{4}$ LL Products, Michigan, USA.

${ }^{5}$ MasterBond, New Jersey, USA. 


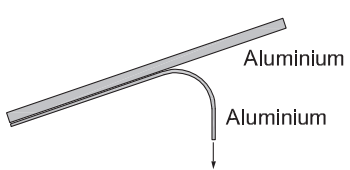

Floating Roller Peel Test (FRPT)

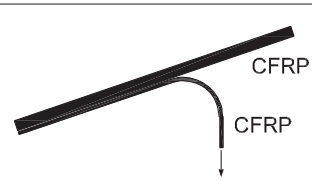

Composite Peel Test (CPT)

Figure 1 Type of specimens.

Selected fracture surfaces of the peel specimens were analyzed after testing using a Scanning Electron Microscope (SEM): JSM-7500F from JOEL (Tokyo, Japan). Prior to the SEM analysis, the fracture surfaces were coated with a thin film of gold $15 \mathrm{~nm}$ thick.

\section{Results}

Two results are obtained from the peel tests: the failure mechanism and the peel strength. The average peel strength and the failure mechanism of the specimens tested in this study are given in Table 2.

Three types of failure mechanisms were observed: (a) adhesive failure (AF), (b) cohesive failure in the adhesive (CF) and (c) intra-laminar failure of the composite (ILFC). The latter was only observed in the Composite Peel Tests.

The adhesive failure indicates a bad adhesion between the adhesive and the adherend, since the failure is at the interface between those two materials. Cohesive failure indicates good adhesion, since the failure is within the adhesive layer and not at the interface. Finally, intra-laminar failure of the composite also indicates good adhesion, since the failure is cohesive within the composite adherend and not at the interface. Furthermore, this type of failure also indicates that the intra-laminar strength of the composite adherend is lower than the debonding strength of the adhesive. The downside of obtaining ILFC is that it deviates the results from characterizing the adhesive to the composites. The \% of failure mode was based on an area estimation of each failure mode by visual observation of the specimens' fracture surface after testing. The $\%$ of failure mode are therefore rough estimations with an error of $\pm 10 \%$. The visual features typical of each failure mode were

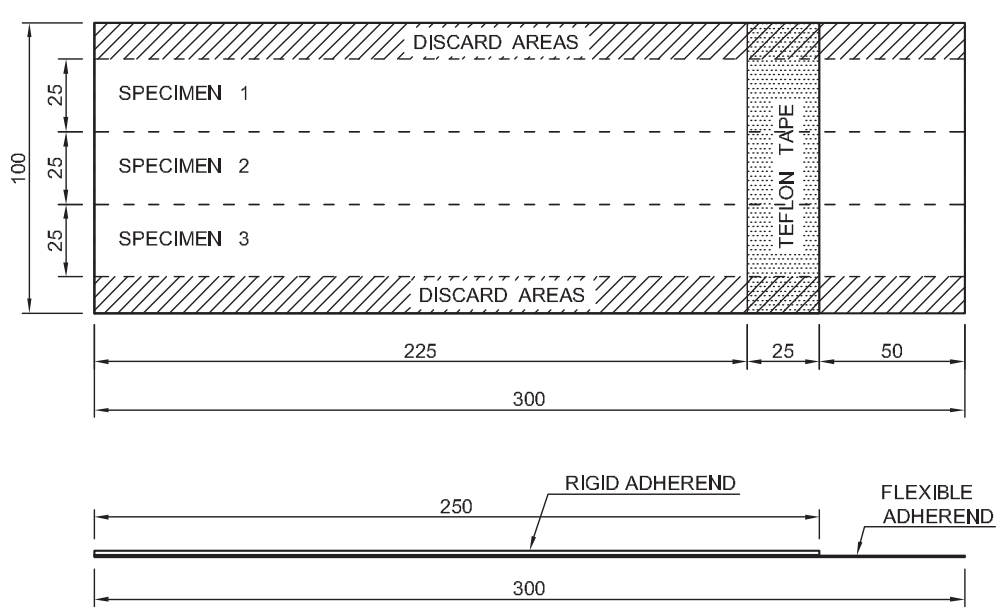

Figure 2 Bonded test panels. 

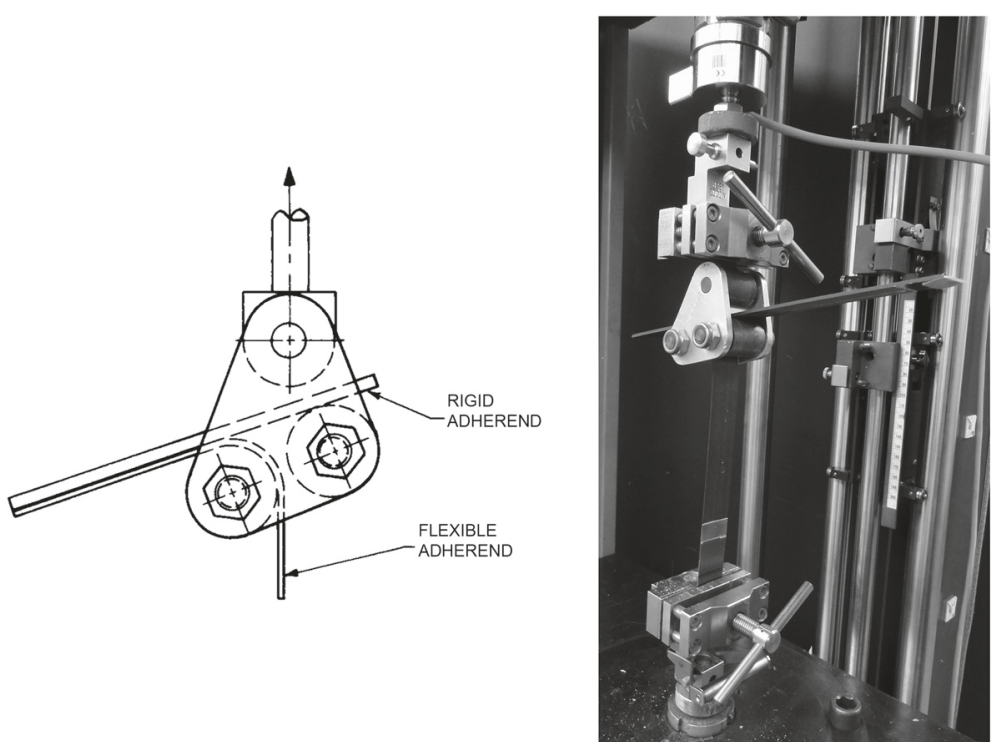

Figure 3 Peel test setup [12].

further confirmed in selected fracture surfaces using optical microscopy and scanning electron microscopy (SEM).

In general, if the failure mode is $100 \% \mathrm{CF}$, the FRPT peel strengths obtained are $20 \%$ to $30 \%$ lower than the ones given in the TDS of the manufacturer (see Table 1). This difference increases if the \% of CF decreases since the peel strengths given by the manufacturer always consider $100 \% \mathrm{CF}$.

Table 2 Test results of the Floating roller peel tests and Composite Peel Test (average peel load and failure modes)

\begin{tabular}{|c|c|c|c|c|c|c|c|c|}
\hline \multirow[t]{3}{*}{ Adhesive } & \multirow[t]{3}{*}{ Temp. } & \multicolumn{3}{|c|}{ FRPT } & \multicolumn{4}{|c|}{ CPT } \\
\hline & & \multirow{2}{*}{$\begin{array}{c}F_{\text {ave }} \\
(\mathrm{N} / 25 \mathrm{~mm})\end{array}$} & \multicolumn{2}{|c|}{ Failure mode } & \multirow{2}{*}{$\begin{array}{c}F_{\text {ave }} \\
(\mathrm{N} / 25 \mathrm{~mm})\end{array}$} & \multicolumn{3}{|c|}{ Failure mode } \\
\hline & & & CF & AF & & $\mathrm{CF}$ & ILFC & AF \\
\hline \multirow[t]{2}{*}{ FM73 } & RT & 275 & $100 \%$ & $0 \%$ & 7 & $0 \%$ & $10 \%$ & $90 \%$ \\
\hline & $+80^{\circ} \mathrm{C}$ & 278 & $100 \%$ & $0 \%$ & 24 & $85 \%$ & $5 \%$ & $10 \%$ \\
\hline \multirow[t]{2}{*}{ EA9695 } & $\mathrm{RT}$ & 52 & $55 \%$ & $45 \%$ & 7 & $5 \%$ & $5 \%$ & $90 \%$ \\
\hline & $+80^{\circ} \mathrm{C}$ & 130 & $95 \%$ & $5 \%$ & 5 & $15 \%$ & $5 \%$ & $80 \%$ \\
\hline \multirow[t]{2}{*}{ EA9696 } & $\mathrm{RT}$ & 297 & $100 \%$ & $0 \%$ & 9 & $15 \%$ & $80 \%$ & $5 \%$ \\
\hline & $+80^{\circ} \mathrm{C}$ & 294 & $100 \%$ & $0 \%$ & 34 & $60 \%$ & $40 \%$ & $0 \%$ \\
\hline \multirow[t]{2}{*}{ EA9686 } & $\mathrm{RT}$ & 179 & $100 \%$ & $0 \%$ & 9 & $10 \%$ & $20 \%$ & $70 \%$ \\
\hline & $+80^{\circ} \mathrm{C}$ & 241 & $100 \%$ & $0 \%$ & 23 & $35 \%$ & $20 \%$ & $45 \%$ \\
\hline \multirow[t]{2}{*}{ AF163-2 } & $\mathrm{RT}$ & 222 & $90 \%$ & $10 \%$ & 8 & $10 \%$ & $90 \%$ & $0 \%$ \\
\hline & $+80^{\circ} \mathrm{C}$ & 265 & $100 \%$ & $0 \%$ & 38 & $60 \%$ & $40 \%$ & $0 \%$ \\
\hline \multirow[t]{2}{*}{ AF191 } & $\mathrm{RT}$ & 54 & $35 \%$ & $65 \%$ & 7 & $5 \%$ & $95 \%$ & $0 \%$ \\
\hline & $+80^{\circ} \mathrm{C}$ & 195 & $95 \%$ & $5 \%$ & 15 & $30 \%$ & $70 \%$ & $0 \%$ \\
\hline \multirow[t]{2}{*}{ AF3109-2 } & $\mathrm{RT}$ & 16 & $0 \%$ & $100 \%$ & 8 & $0 \%$ & $100 \%$ & $0 \%$ \\
\hline & $+80^{\circ} \mathrm{C}$ & 190 & $30 \%$ & $70 \%$ & 12 & $35 \%$ & $45 \%$ & $20 \%$ \\
\hline \multirow[t]{2}{*}{ L-8100 NE } & $\mathrm{RT}$ & 104 & $50 \%$ & $50 \%$ & 10 & $5 \%$ & $90 \%$ & $5 \%$ \\
\hline & $+80^{\circ} \mathrm{C}$ & 86 & $37 \%$ & $63 \%$ & 9 & $10 \%$ & $80 \%$ & $10 \%$ \\
\hline \multirow[t]{2}{*}{ Sup10HT } & $\mathrm{RT}$ & 66 & $100 \%$ & $0 \%$ & 9 & $65 \%$ & $20 \%$ & $15 \%$ \\
\hline & $+80^{\circ} \mathrm{C}$ & 69 & $80 \%$ & $20 \%$ & 9 & $60 \%$ & $0 \%$ & $40 \%$ \\
\hline
\end{tabular}




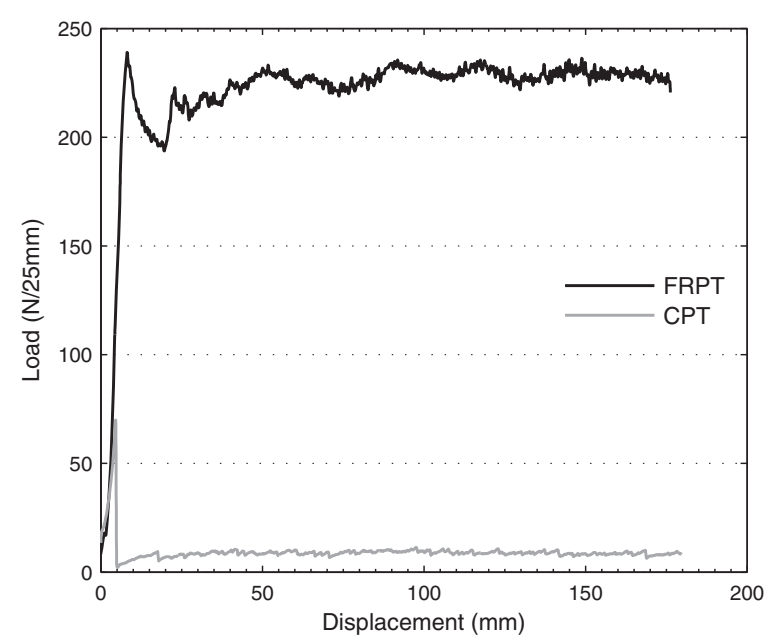

Figure 4 Example of load-displacement curves measured during FRPT and CPT for the adhesive AF163-2 at room temperature.

Figure 4 shows examples of load-displacement curves measured during the FRPT and CPT. The average peel strength was determined along $150 \mathrm{~mm}$ of displacement, disregarding the first $15 \mathrm{~mm}$ after a first peak (decrease of about 5\%). This procedure for determining peel strength values is in accordance with ASTM standard D3167 [1].

Figures 5 and 6 show the FRPT and CPT results for four adhesives, as an example (EA9696, AF163-2, AF191 and Supreme10HT).

Firstly, one can observe that in most cases, increasing the temperature increases the \% of cohesive failure followed by an increase in the peel strength. For FRPT, since there is only two failure modes, the increase of cohesive failure results from a decrease of adhesive failure. This indicates that, there is an increase of adhesion performance between the aluminium and adhesive with temperature.

For CPT, the increase of cohesive failure is either followed by a decrease of adhesive failure or a decrease of ILFC, or a combination of both. However in most cases tested, the increase of the cohesive failure with temperature is followed by a decrease of the ILFC. For the CPT performed at RT, and as long as the failure does not occur at the interface $(\% A F<20 \%)$, the \%ILFC is higher than the \%CF. At high temperatures, this tendecy is the reverse, higher \%CF than \%ILFC. This might be due to the fact that at higher temperatures

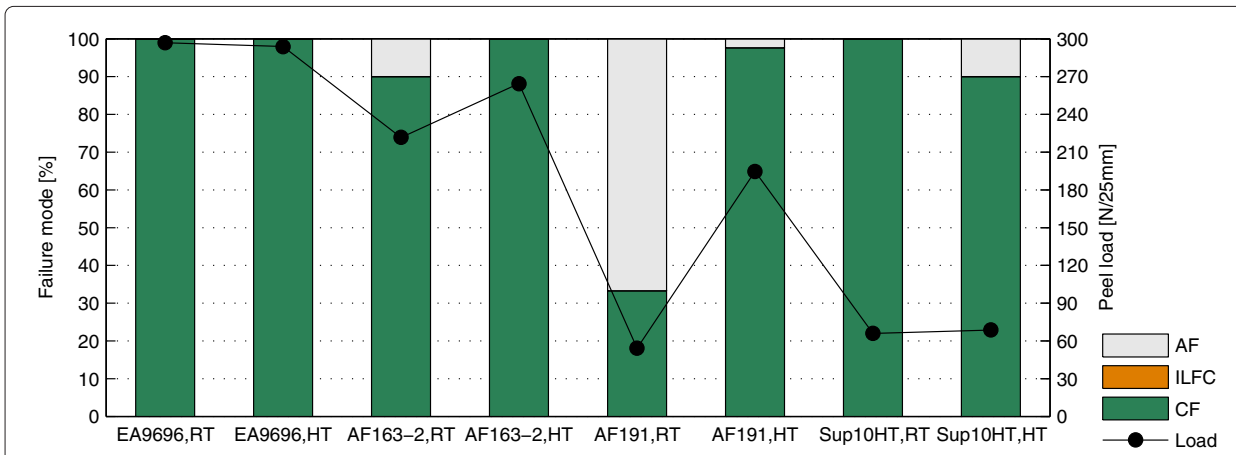

Figure 5 Example of FRPT results (metal bonding) for four adhesives at RT and at $+80^{\circ} \mathrm{C}(\mathrm{HT})$. 


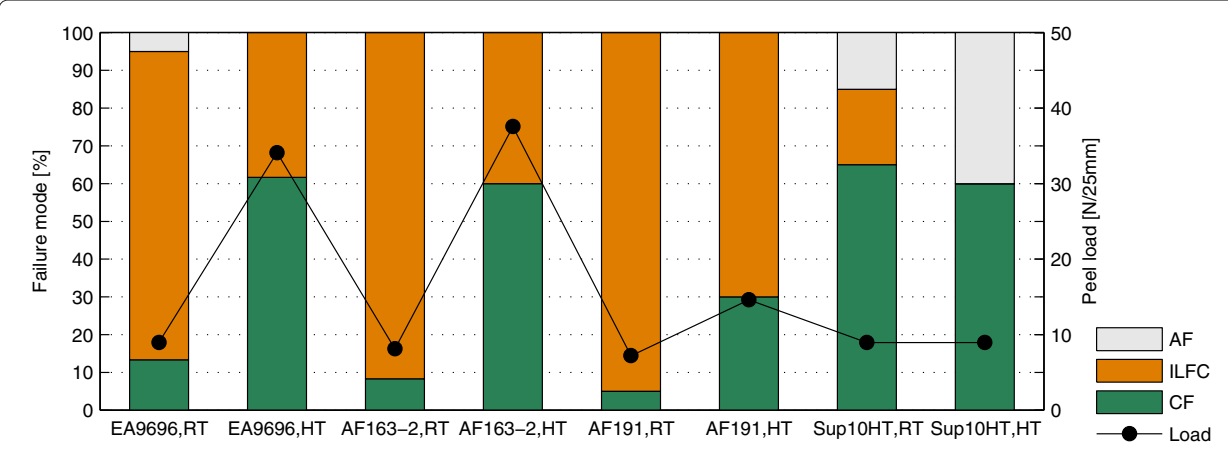

Figure 6 Example of CPT results (composite bonding) for four adhesives at RT and at $+80^{\circ} \mathrm{C}(\mathrm{HT})$.

the composite resin matrix and the fibre/resin interface become more flexible, allowing larger deformation before failure, therefore "enabling" cohesive failure rather than intralaminar failure. This tendency can be observed for AF163-2, EA9696 and AF191. This results in higher peel strengths at high temperatures than at RT. It has been shown by previous studies published by the authors that cohesive failure results in higher strengths than ILFC [12].

Secondly, the peel strengths obtained from the CPT are significantly lower than from the FRPT, even if the percentage of failure modes is similar. As it has been addressed in previous studies of the authors, peel loads can differ significantly when peeling off different adherend materials, and it does not mean a poor interface adhesion [12]. Peel loads can only be compared if using exactly the same type of flexible adherend (peeling off member). Only then, peel loads can be used as an indication of adhesion properties.

Table 3 makes a summary of the adhesion performance of each adhesive. The adhesion performance was considered as "Good" if the cohesive failure plus the intra-laminar failure of the composite are higher or equal to $80 \%$. The adhesion performance was considered as "Bad" if the adhesive failure is higher or equal to $80 \%$. The cases in between were considered as "Neutral". From the nine adhesive tested in this study, AF163-2 and EA9696 have the best adhesion performance to both CFRP and Aluminium.

\section{Discussion}

Figures 7 and 8 plot the peel strengths obtained from the FRPT against the peel strengths obtained from the CPT, at room temperature and at high temperature, respectively.

At room temperature, the data is distributed along a horizontal line. This means that there is no relationship between the peel strength of the FRPT and the peel strength of the CPT at RT. This is due to the fact that the major failure mode obtained from the CPTs at RT was intra-laminar failure of the composites. Therefore, the strength measured in CPT is from the composite which is unrelated with the strength of the adhesive obtained from

Table 3 Adhesion performance of the nine adhesives against Aluminium (FRPT) and Composites (CPT)

\begin{tabular}{cccccccccc}
\hline & FM73 & EA9695 & EA9696 & EA9686 & AF163-2 & AF191 & AF3109-2 & L-8100 NE & Sup10HT \\
\hline Aluminium & Good & Neutral & Good & Good & Good & Neutral & Bad & Neutral & Good \\
Composite & Bad & Bad & Good & Neutral & Good & Good & Good & Good & Neutral \\
\hline
\end{tabular}




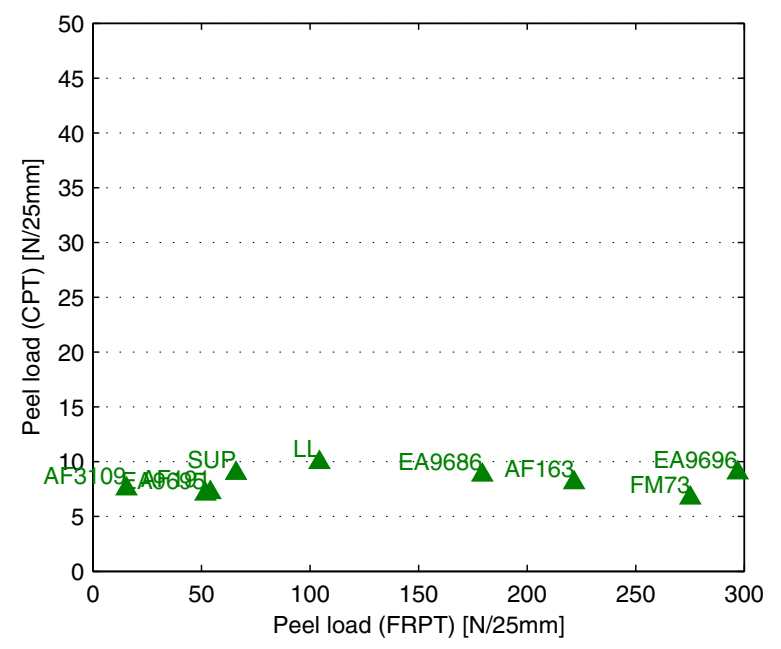

Figure 7 Relation between peel load of floating roller peel tests and composite peel tests at room temperature.

the FRPT. No distinction can be made between different adhesives from the CPTs at RT, since all tests give a property of the common adherend (composite).

However, at high temperature, the cohesive failure increases in the CPTs, allowing to make a distinction between different adhesives. The peel strength in the CPTs is linearly related with the peel strength from the FRPTs. This means that, if the major failure mode is cohesive, an adhesive which has a relatively high peel strength in Aluminium peel tests, it will also have a relatively high peel strength in composite peel tests. This can be observed when comparing for example the adhesive Sup10HT with the adhesive AF1632. For FRPT, AF163-2 has higher peel strength than Sup10HT, and the same happens for $\mathrm{CPT}$ at high temperatures when cohesive failure is the dominant failure mode. If the failure mode is cohesive, the comparison between adhesives' peel strength is consistent disregarding of the type of peel-off adherend.

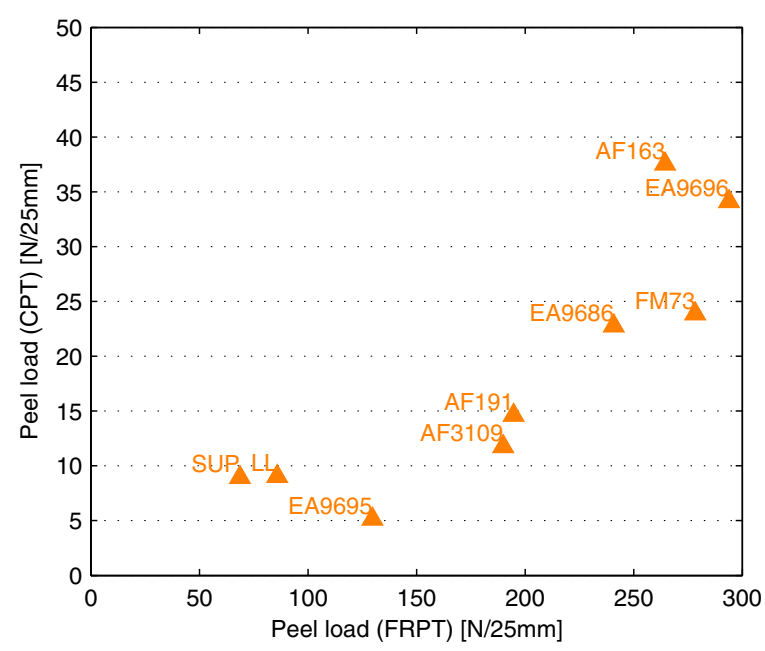

Figure 8 Relation between peel load of floating roller peel tests and composite peel tests at high temperature $\left(+80^{\circ} \mathrm{C}\right)$. 
Differences in peel strength (with 100\% cohesive failure) results from different ductilities of the adhesive material: higher ductility results in higher peel strengths. Therefore, from what has been written previously, AF 163-2 is more ductile than Sup10HT, since the peel strength of $100 \% \mathrm{CF}$ of AF163-2 is higher than the peel strength of $100 \% \mathrm{CF}$ of Sup10HT. This conclusion is supported by the fracture surfaces analyses in SEM hereafter.

Representative Scanning Electron Microscope (SEM) pictures of the fracture surfaces of two adhesives are shown in Figures 9 and 10.

Figure 9 shows the fracture surfaces of the adhesive AF163-2 at the rigid adherend side of the bond. Considering the FRPT fracture surfaces (1st row), a clear distinction can be seen between cohesive failure (CF) and adhesive failure (AF). At room temperature (RT) as well as at $+80^{\circ} \mathrm{C}(\mathrm{HT})$, the fracture surface of adhesive failure is quite smooth and flat. Contrary to this, the fracture surface of cohesive failure is significantly more rugged. There is no significant differences between the fracture surface of CF and AF at RT and HT.

Considering the CPT fracture surfaces (2nd row), the three failure modes can be observed: intra-laminar of the composite (ILFC), adhesive failure (AF) and cohesive failure (CF). The fracture surface of the cohesive failure has the same characteristics as for the CF observed for the FRPT. This means that the fracture mechanism of the CF is independent of the peeling-off adherend (composite or Aluminium). This supports the conclusion taken previously from Figure 8 , the strength resulting from the same fracture mechanisms is comparable disregarding of the peel-off adherend. This has been observed for the results at HT when comparing, for example, AF163-2 with Sup10HT. Disregarding the peel tests used, AF163-2 has higher peel strengths than Sup10HT. This also supports the conclusion that, the difference between the peel strengths obtained from FRPT and

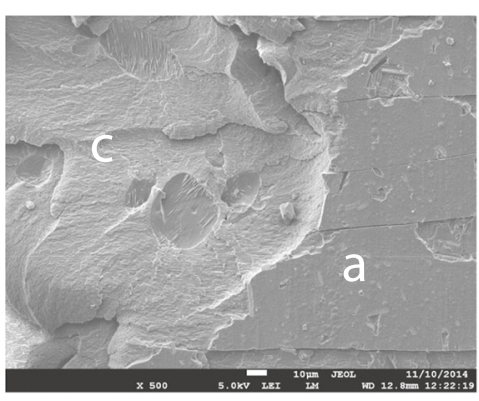

AF163-2: FRPT at RT

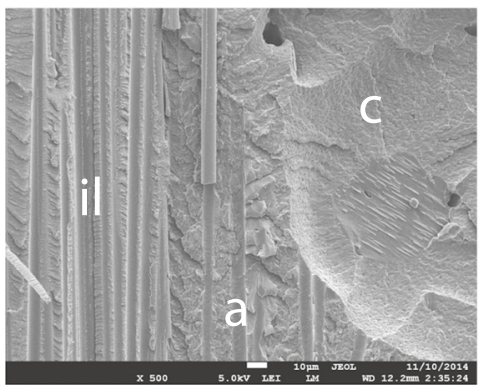

AF163-2: CPT at RT

a: adhesive failure; c: cohesive failure;

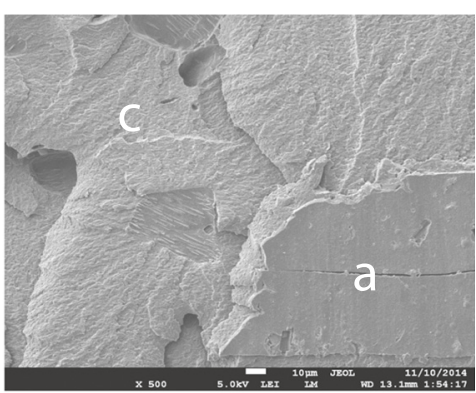

AF163-2: FRPT at HT

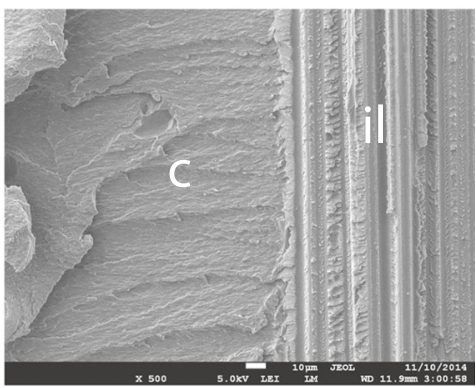

AF163-2: CPT at HT

il: intra-laminar failure

Figure 9 SEM AF163-2. 


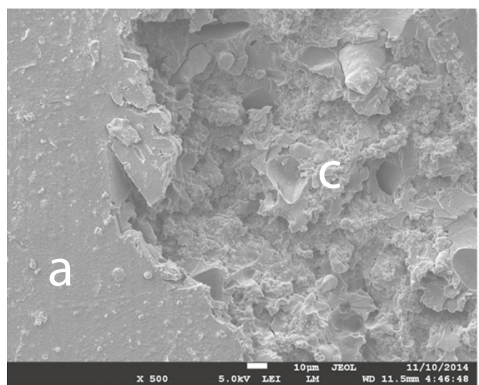

Sup10HT: FRPT at HT (Ra)

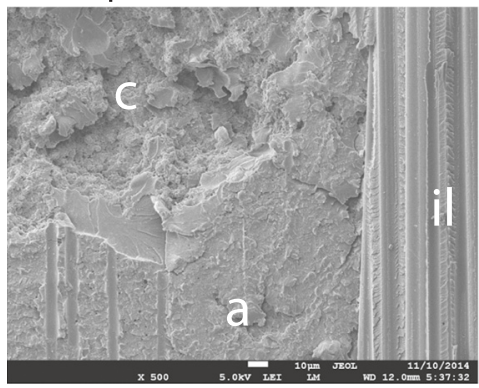

Sup10HT: CPT at RT (Ra)

a: adhesive failure; c: cohesive failure;

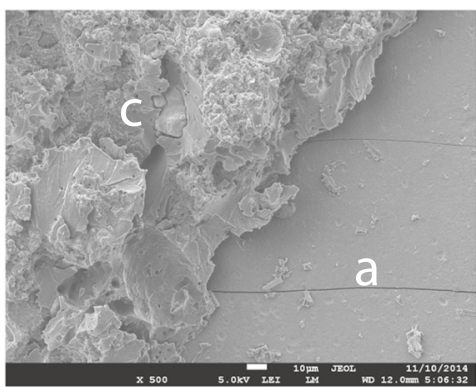

Sup10HT: FRPT at HT (Fa)

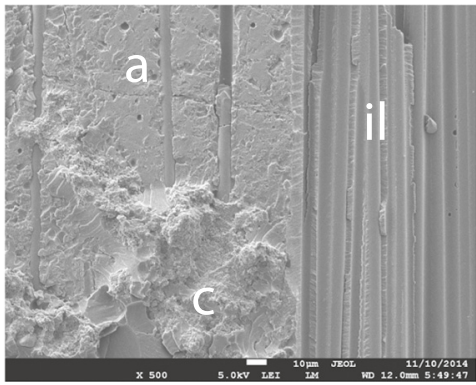

Sup10HT: CPT at HT (Fa)

il: intra-laminar failure

Figure 10 SEM Supreme 10HT.

CPT for bonded joints with the same failure modes are due to the differences in stiffness and ductility of the peeling off adherend and not due to lower cohesive strength.

In the fracture surface of the ILFC, one can observe resin-free carbon fibers as well as carbon fiber in-print, confirming the intra-laminar failure of the composite laminate. Finally, one can observe a flatter and smoother surface (adhesive failure). Although is not as smooth as observed for the FRPT, it is a clear interface failure.

Figure 10 shows the fracture surfaces of the adhesive Supreme 10HT at the rigid adherend ( $\mathrm{Ra})$ side and at the flexible adherend $(\mathrm{Fa})$ side of the joint. Firstly, one can observe that the fracture surface of the cohesive failure of Sup10HT is significantly more shattered and rough than the one for the AF163-2. This indicates that Sup10HT has a more fragile rupture than AF163-2. This is in accordance with the conclusion given by the peel strength: AF 163-2 is more ductile than Sup10HT. The fracture surface of adhesive failure at the Sup10HT specimen is very similar to the one at AF163-2 (smooth and flat). As observed for AF163-2, the CF's fracture surfaces of Sup10HT look alike disregarding of which type of peel off material is used, composite adherends or aluminium adherends.

\section{Conclusions}

This paper introduces a new type of peel tests dedicated to composite bonding: Composite Peel Tests. This new type of peel tests is inspired on the standard floating roller peel test widely used for metal bonding.

The aim of this study was to investigate the potential of the newly developed peel tests. To this end, peel tests were performed with nine different type of adhesives and at two environmental temperatures, room temperature and $+80^{\circ} \mathrm{C}$. 
From the analysis of the results, the following conclusions were drawn:

- When assessing interface quality of composite bonding using peel tests, a third failure mechanism is likely to occur, beyond the conventional two failure modes (adhesive failure and cohesive failure): intralaminar failure of the composite.

- The intra-laminar failure of the composite indicates good adhesion, since the failure is cohesive in one of the adherends and not at the interface.

- In most cases of good adhesion, increasing the temperature favors cohesive failure of the adhesive in detriment of intra-laminar failure of the composite.

- The absolute values of the peel strengths can only be compared if using exactly the same type of flexible adherend (peeling-off member). Only then, the peel strengths can be used as an quality indicator of interface adhesion.

- The difference between the peel strengths obtained from floating roller peel tests and composite peel tests for joints with the same failure modes are due to the differences in stiffness and ductility of the peeling-off adherend and not due to different bond quality.

- The fracture mechanism of a cohesive failure is independent of the peeling-off adherend (composite or Aluminium).

- If the failure mode is cohesive, the comparison between adhesives' peel strength is consistent disregarding of the type of peel-off adherend.

- The peel strength resulting from the same fracture mechanisms is related disregarding of the peel-off adherend.

- From the nine adhesive tested in this study, AF163-2 and EA9696 have the best adhesion performance to both composites and Aluminium.

- The results show that Composite Peel Tests are suitable to assess interface adhesion of composite bonding.

Competing interests

The authors declare that they have no competing interests.

Authors' contributions

STF - carried out the experimental tests and analyses and drafted the manuscript. JS - supervised the experimental analyses and corrected the manuscript. Both authors read and approved the final manuscript.

\section{Acknowledgements}

This research was supported by Materials innovation institute (M2i) and Fokker Aerostructures.

Received: 30 December 2014 Accepted: 30 January 2015

Published online: 24 March 2015

References

1. ASTM-D3167:10 (2010) Standard Test Method for Floating Roller Peel Resistance of Adhesives. ASTM International

2. Bishopp JA, Sim EK, Thompson GE, Wood GC (1988) The Adhesively Bonded Aluminium Joint: The Effect of Pretreatment on Durability. J Adhes 26:2-3, 237-263

3. Hart-Smith $L$ (1999) A peel-type durability test coupon to assess interfaces in bonded, co-bonded, and co-cured composite structures. Int J Adhes Adhes 19(2-3):181-191. doi:10.1016/S0143-7496(98)00033-5

4. Sargent JP (2005) Durability studies for aerospace applications using peel and wedge tests. Int J Adhes Adhes 25(3):247-256

5. Crocombe AD, Adams RD (1982) An Elasto-Plastic Investigation of the Peel Test. J Adhes 13:3-4, 241-267

6. Kim J, Kim KS, Kim YH (1989) Mechanical effects in peel adhesion test. J Adhes Sci Technol 3(1):175-187. doi:10.1163/156856189X00146

7. Wei Y, Hutchinson J (1998) Interface strength, work of adhesion and plasticity in the peel test. Int J Fract 93(1-4):315-333. doi:10.1023/A:1007545200315

8. Van Voast K, Blohowiak P, Osborne J, Belcher M (2013) RAPID TEST METHODS FOR ADHESIVES AND ADHESION. In: SAMPE 2013 Proceedings: Education \& Green Sky - Materials Technology for a Better World. Society for the Advancement of Material and Process Engineering, Long Beach, CA, May 6-9, 2013. pp 628-636 
9. Flinn BD, Clark BK, Satterwhite J, Voast PJV (2008) Influence of peel ply type on adhesion bonding of composites. In: SAMPE 2008 Proceedings. Society for the Advancement of Material and Process Engineering, Long Beach, CA, June 3-7, 2008. pp 1-26

10. Holtmannspötter J, Czarnecki Jv, Gudladt H-J (2010) The use of power ultrasound energy to support interface formation for structural adhesive bonding. Int J Adhes Adhes 30(3):130-138. doi:10.1016/j.ijadhadh.2009.10.002

11. Riul C, Tita V, de Carvalho J, Canto RB (2012) Processing and mechanical properties evaluation of glass fiber-reinforced PTFE laminates. Compos Sci Tech 72:1451-1458. doi:10.1016/j.compscitech.2012.05.021

12. Teixeira de Freitas S, Sinke J (2014) Adhesion Properties of Bonded Composite-to-Aluminium Joints Using Peel Tests. J Adhes 90(5-6):511-525. doi:10.1080/00218464.2013.850424

Submit your manuscript to a SpringerOpen ${ }^{\odot}$ journal and benefit from:

- Convenient online submission

- Rigorous peer review

- Immediate publication on acceptance

- Open access: articles freely available online

- High visibility within the field

- Retaining the copyright to your article

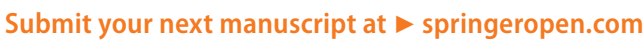

